\title{
Experimentation in Architecture: Pavilion Design
}

\author{
By Gonca Tuncbilek ${ }^{*}$
}

\begin{abstract}
Since the Great Exhibition in London in 1851, the field of exhibition design has become an inevitable impact on both architectural practice and discourse. Any exhibition design offers 'new' architectural problem-solving techniques, and this experimental process generates a direction to apply new architectural methods, new materials, and new concepts. This process leads to searching, experiencing, and opening up new possibilities without the constraints of the established rules. Thus, architects can experience what the future holds for spatial design. Architectural design enriches through experimenting with new approaches and new materials. This paper suggests that architectural experimentation can be provided in terms of Serpentine Gallery Pavilions as well as challenging the architect's role in re-establishing the conventional architectural thought. Thus, the architect is searching for new architectural possibilities and exploring the limitations of interpretation. Pavilion design can be considered as an architectural phenomenon in the light of this experiment to expose something 'new' and also in an innovative manner. Not only does the pavilion layout influence on its setting, but it also has the ability to redefine contemporary architecture, discourse, and practice. The pavilion's very limited nature requires the architect to design a clear-cut expression, develop a simple concept, and to find different methodologies orland solutions for the 'temporality' of architecture. This experimentation not only has an impact on architectural practice and discourse but also leads to comment on and critique new possibilities in the field of architecture. Architects gain the freedom to experience the 'new' architecture through this experimental process.
\end{abstract}

\section{Introduction}

In Nikolaus Pevsner's Dictionary, 'pavilion' is defined, in its general terms, as a 'lightly constructed, ornamental building, often used as a pleasure-house or summer house in a garden and also as a projecting subdivision of some larger building. ${ }^{1}$ In addition, as stated in the dictionary, the pavilions are designed as single-bodied buildings located within the park or garden of a larger edifice. They are intended as light constructions that can be quickly erected and dismantled to be re-constructed in different times and locations. It serves as a pleasure-house that indicates the function of these structures. These temporary structures reflect certain common characteristics, such as flexible use, standardization of architectural elements, ease of transport, quick/easy/rapid construction, and dismantling. They are nomadic by their very nature, so there is no trace left behind when they are gone. Their transient nature suggests that they can be used for a variety of short-

\footnotetext{
*Research Assistant, METU - Middle East Technical University, Turkey.

1. J. Fleming, H. Honour and N. Pevsner, Dictionary of Architecture and Landscape Architecture (England: Penguin Books, 1999), 427.
} 
term functions. They can be used as an extension of some larger buildings to serve to minimalist functions.

The definition of the term 'temporality' relates mainly to the lifespan of the architecture structure, which is relatively short in the case of pavilions. Moisés Puente claims that the temporary structures have died young and that their temporary existence does not permit the passage of years. ${ }^{2}$ Although the short lifespan of temporary architecture is inherently negative, there are compelling advantages that transcend their period of existence, their impact can be longlasting, creating a memory of architectural practice, projecting the power of focus, perception, construction, and their inevitable destruction forms a part of their relevance. Moreover, the power of the pavilion's experience gives importance to its evaluation and effect, as well as its meanings, and thus diminishes the relevance of its temporary nature.

As a representation of the temporary architecture, the design of the pavilions can be interpreted as an appropriate medium for experimenting, investigating the borders/boundaries of architecture, testing grounds, exploring new architectural concepts, methods, and materials without the limitations of the established functions and their economics. In the light of this statement, this paper analyzes the Serpentine Gallery Pavilion designs to understand the possibilities of the transitory nature in architectural domain.

These temporary structures differ in several ways from conventional architectural practices. They are transitory since their period of existence is scheduled from the very beginning; they can be built, constructed, and dismantled quite quickly. Furthermore, the architects themselves can build these kinds of structures. Besides, they are usually inexpensive, relatively smaller, and lighter than permanent structures of a similar nature. In brief, they are appropriate for investigating the boundaries of architecture in a reduced manner. ${ }^{3}$ Architects can re-examine and explore the construction methods, the budgetary requirements, and the scales of these structures as a way of searching the 'new' in both architectural practice and discourse.

Designed on a variety of scales, such as exhibition complexes, exhibitions, exposition, installations, and pavilions, it has served as a testing ground for innovative solutions, tools, instruments, and materials through the implementation of the latest tendencies in architecture. In architecture, these temporary structures have an essential role both in the local and global stratum, and even though they serve their purpose for a relatively limited period, they usually have the potential to attract the attention of the press, the wider public, the user and the architects.

Exhibition spaces, expositions, and pavilions invite architects and the public to observe, touch, enter, experience, interact, comment on, and think about architecture. As a 'new' architectural representation, temporary structures have grown as a spatial form in architectural research, discourse and practice. Both, the designer/architect and the observer/user of the pavilion are directed by these

2. M. Puente, The Exhibition Pavilions: 100 Years (Barcelona: Editorial Gustavo Gili, SA, 2000), 8 .

3. S. Bonnemaison and R. Eisenbach, Installations by Architects (New York: Princeton Architectural Press, 2009), 14. 
structures to open debate on architecture, which has an impact on the opening up of various possibilities in architectural space design. In this respect, pavilions can be interpreted as an agent for re-defining and re-formatting the boundaries of the architectural discipline.

\section{Experimental Architecture in terms of Materials/Methods}

Since the Great Exhibition was held in London in 1851, the field of exhibition design has been made a noticeable impact on architecture. The domain of architectural design is related to practical issues such as planning, the conceptualization of structures, function, and accessibility, but also user demands, including comfort, safety, and adaptation. Experimentation can be re-emphasized with research, analysis, and discussion in architecture, and can be based on the relationships among architectural concepts. 'Experimental Architecture' has developed as a movement in architectural research, discourse, and practice as a subject dealing with the experimentation of new ideas, new methods, and new materials.

Pavilion design has a powerful influence on creativity in architectural discourse, research, and practice as a form of temporary architecture. As a design method, temporary architecture generates ideas to take the place of problemsolving and completed solutions and operates outside the established rules and classifications of 'problem-solving architectural design activity.' Moreover, it is also less concerned with the constraints of engineering than in searching, experiencing and opening up new possibilities, and recognizing what the future holds for spatial design.

Experimenting with the new materials and new methods enriches architectural practice and discourse. In this respect, this paper suggests that pavilion design can be interpreted as a laboratory for experimentation in architecture. This indicated that the critical position of pavilion design could be considered in terms of both materials and methods as the conceptual base from which experimentation in architecture can be launched. An architect's choices of materials and techniques can be a key to creating possibilities and re-setting the architectural limitations. In this manner, in terms of challenging/questioning the material, there are two different kinds of knowledge, the first is related to its possibilities and limits, as well as understanding the architect's abilities as human beings.

Christina Lodder states that the crucial point of these laboratory works is that they are not undertaken for the creation of an end product or any immediate utilitarian purpose, instead they are designed with the understanding that such experimentation may eventually contribute to the resolution of some functional task. ${ }^{4}$ Temporary structural design is the generation process in which examines, explores, and experiences the model rather than the end product. The main part of the experimentation is the generator process of these temporary structures, while the function/purpose of these structures is to facilitate testing and exploration,

4. C. Lodder, Russian Constructivism (CT; London: Yale University Press, 1993), 7. 
developing solutions for utilitarian requirements. Peter Smithson defines these structures as "real before the real," ${ }^{, 5}$ serving as a mock-up of the permanent architectural practices and can be viewed as grounds for the testing ground of new architectural concepts, expressions, constructions, techniques, methods, spatial figurations, and materials.

Temporality is mainly related to both limitations and opportunities for experimentation. This relationship provides an architect with a fresh medium in which it is possible to practice, learn, observe experience and explore 'new' opportunities in architecture through new building methods. Depending on the architect's perception and interpretation, this experimentation and exploration can change. Zaha Hadid, a highly creative architect, was interested in the temporality of semi-closed space and defined the 2000 Serpentine Gallery Pavilion ${ }^{6}$ as a public space that could not be separated from the park, so there was no rigid boundary. The pavilion made use of simple and rapidly demountable materials to mirror its temporality. While the budget was limited to designing an improved tent, Hadid's pavilion had a significant impact on architectural discourse ${ }^{7}$ in London (Figure 1).

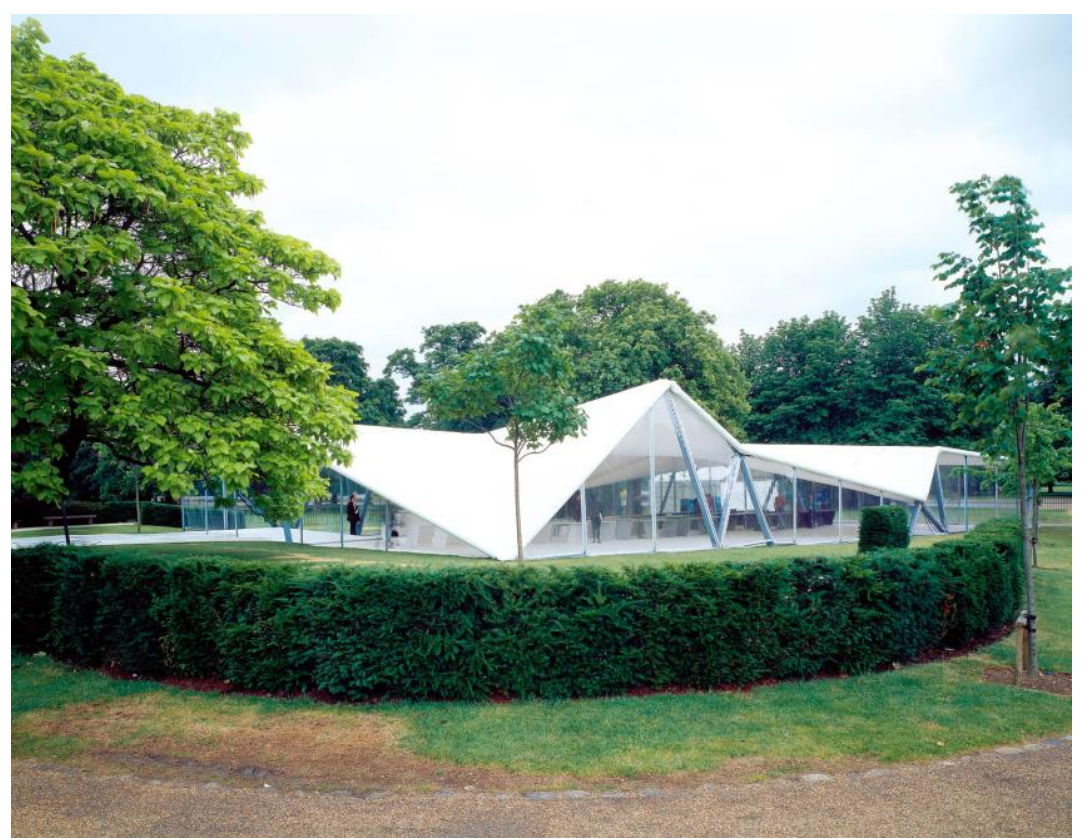

Figure 1. The 2000 Serpentine Gallery Pavilion by Zaha Hadid

Source: Serpentine Gallery 5 May 2018. www.serpentinegallery.org.

5. P. Smithson, "The Masque and the Exhibition: Stages Toward the Real," in Language of Architecture: Lectures, Seminars, and Projects. International Laboratory of Architecture and Urban Design. (ed.) Giancarlo Di Carlo (Urbino, Florence: Sansoni, 1982), 62.

6. The Serpentine Gallery Pavilions has been the case of the author's completed master thesis entitled "Temporary Architecture: The Serpentine Gallery Pavilions," supervised by Prof. Dr. Ayşen Savaş (Turkey: Middle East Technical University, 2013).

7. There are several acclaimed architectural magazines that have given space to these temporary pavilions, including Architectural Review, Architectural Design, A+U, Detail and Architectural Record. 
Zaha Hadid's design experimentation reminds a former explanation of Le Corbusier. As indicated by the title 'Architecture: The Expression of the Materials and Methods of our Times' suggested, Le Corbusier's focus was on the issue, 'Is architecture not determined by new materials and new methods?', dwelling on the change of materiality and methods and their development. ${ }^{8}$ Le Corbusier complained about the reproduction of past architectural styles and techniques. At any given time, the architectural practice should be an expression of the present circumstances, not belated incorporation of previous architectural endeavors.

'We still permit our houses to lie close to a damp and unhealthy ground. We are still discussing whether or not our houses are to have roofs, while roof gardens bring health, joy, and an upheaval of plan replete with magnificent liberties. We are still building our houses of stone, with massive walls, while light and slender cars are speeding at sixty miles an hour through snows or under the tropical sun. We are still employing masons and carpenters on the job, to work in rain or snow, or fair weather, while factories could turn out to perfection that which we accept poorly executed. And so forth and so on."9

Following this statement, Le Corbusier questioned how architects would adapt so many innovations to their work today, how they would select for their building's unknown forms of construction, and how they could arrange architectural phenomena to introduce something new and aesthetically innovative. As he stated above, it is time to think about 'new' in architectural practice and discourse, being an undeviating advocate of the temporality of forms, design, and practices in the discipline. As such, architecture should be 'an endeavor innovative progressive rather than a dogmatic adherence to past prerequisites and set methodologies, ${ }^{10}$ and the place of pavilions in this context would resonate positively in Le Corbusier's judgment. The architectural community can attach more serious and objective considerations to the relevance of temporality in architectural discourse, as exhibited in the case of pavilions, initially through the materiality and methods of architectural practice. Such experimentation in architectural context could open up new fields and visions.

Le Corbusier claimed that contemporary architecture should contain innovations, new technologies, and new construction forms, as well as an aesthetical perception. As suggested by Le Corbusier, Daniel Libeskind has explored new materials and methods of the present circumstances as an expression of experimentation in architecture. When designing the 2001 Serpentine Gallery Pavilion, Libeskind delved into his interest in folding techniques, being influenced by origami, and adopting the same principles in his folded structures (Figure 2). Since a rigid structural load-bearing frame supported each folding aluminum panel, the structural strength of the folded framework came from its being. The architect achieved stability through the use of simple forms such as triangles and

8. Le Corbusier, "Architecture: The Expression the Materials Methods of our Times?" in Rethinking Technology (ed.) William Braham and Jonathan A. Hale (The United States of America and Canada: Routledge, 2007), 39.

9. Ibid, 40.

10. Ibid. 
rectangles, although the outcome of the complete design was complex and unorthodox.

The pavilion was named 'Eighteen Turns,' referring to the 18 folds in the structure. Using angled metallic surfaces provided an integrated interactive space exploration both inside and outside, blurring the boundaries between the spaces. Libeskind stated that although the pavilion would disappear, it would leave an unforgettable afterimage and an exceptional resonance on a unique space. ${ }^{11} \mathrm{He}$ also claimed that pavilion design offered several ways of experimentations and explorations of the place: before the pavilion, at the present time of the pavilion, and after the pavilion gone. Underlining a long-lasting effect on the site where these temporary structures stood, they can incorporate the methods and materials of future architecture and create a new vision of architecture for both a physical and an aesthetic impact on a neighborhood or city.

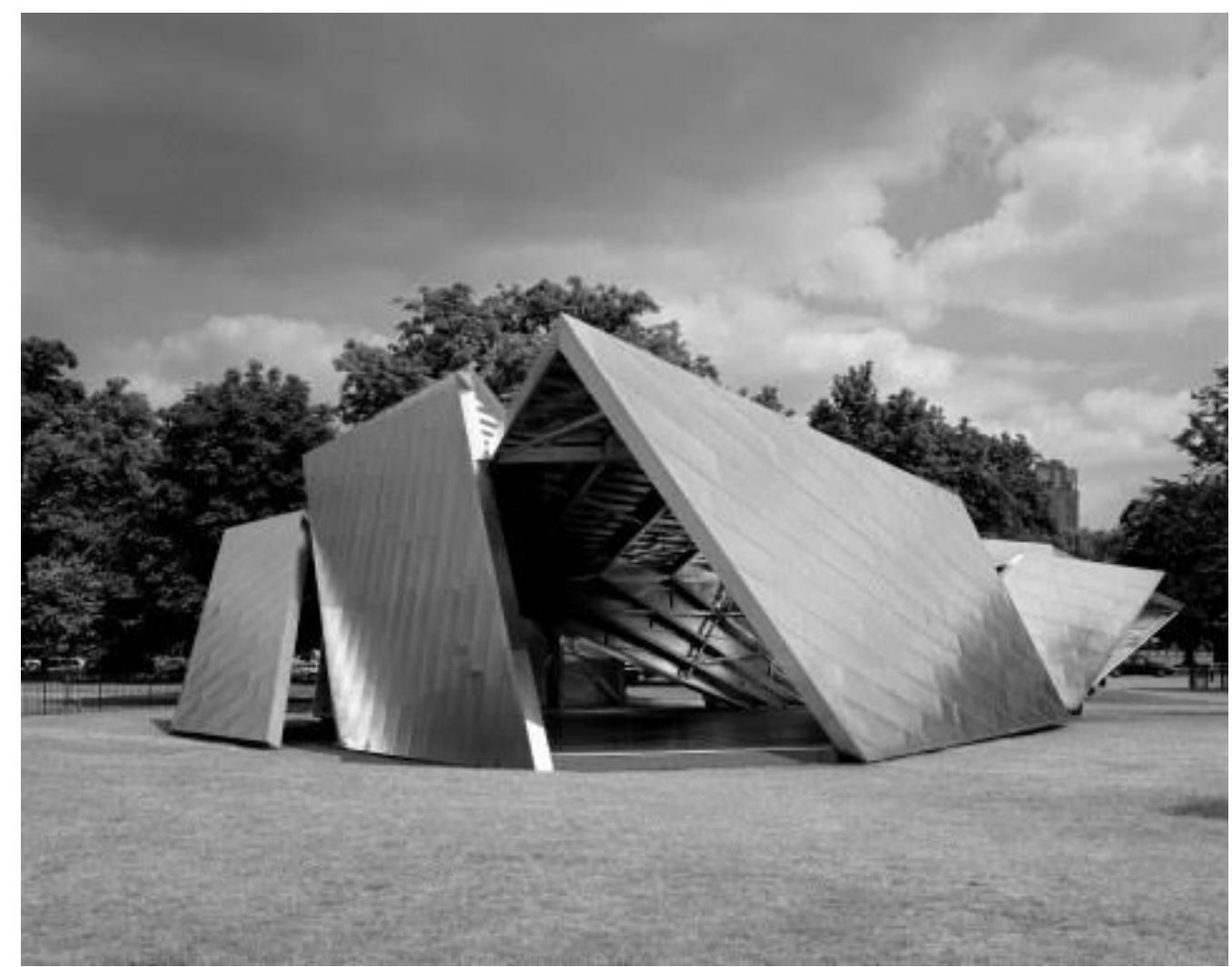

Figure 2. The 2001 Serpentine Gallery Pavilion by Daniel Libeskind

Source: Serpentine Gallery 5 May 2018. www.serpentinegallery.org.

The architects of the Serpentine Gallery Pavilions investigate the boundaries of experimental architecture and re-interpret the temporality through their designs. An investigation of these pavilions can help in understanding the ingenuity and creativity of architecture since through these temporary structures, and the architect can experience new materials and new methods. Architect and critic Mark Robbins underlined that the pavilions are distillations of experience in

11. P. Jodidio, Serpentine Gallery Pavilions (Spain: Taschen, 2011), II.06. 
architectural practice. ${ }^{12}$ The architect can gain experience in terms of new materials, methods, and techniques on building performance because the period of use and construction are limited. Moreover, a limited budget forces the architect to create a work of clear-cut expression.

Temporary structures can propose evidence of what is to come in future architecture, even if the architectural project is realized or not. The design process itself may have a powerful impact on architectural practice and discourse, so the experimentation is not only related to the end product. Designing the 2004 Serpentine Gallery Pavilion, MVRDV supported this statement in their reinterpretation of the definition of 'pavilion,' although it was never built since it was extremely challenging in terms of budget, the complexity of construction and disabled access. They designed an artificial sky within a galvanized steel frame structure under which to cover the entire Serpentine Gallery was to be buried, which was a refreshing departure from the idea of a more-or-less-pretty object standing on a lawn (Figure 3).

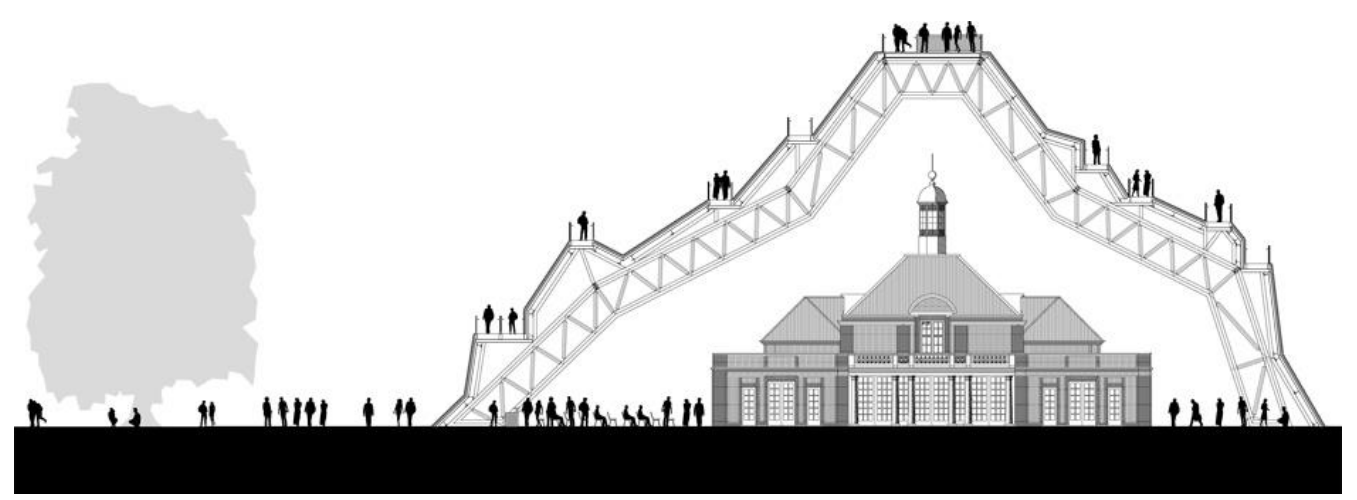

Figure 3. Section of the Serpentine Gallery Pavilion of MVRDV

Source: Serpentine Gallery 5 May 2018. www.serpentinegallery.org.

This unique unbuilt pavilion was to be over $23 \mathrm{~m}$ high, resembling a giant three-dimensional lobby, and would have been the highest of all Serpentine Pavilions if it had been completed. MVRDV discussed and explored new methods for exhibiting the Gallery within the pavilion. The design of this pavilion provided MVRDV to experiment with the construction of new materials and structures not just of buildings, but also information systems and data, as a continuous exchange of space and material in a contemporary architectural domain. They preferred to not develop an additional structure in order to form a stronger relationship between the pavilion and the Gallery, but rather to extent to the Gallery according to which the pavilion could not be separated physically from its Gallery.

Cecil Balmond, Deputy Chairman of Arup, mentioned that MVRDV's project had been a part of an exploration of new materials, forms and methods of architectural practice, and research into information systems and data. Even though the project was not realized, it raised many debates and had a significant impact on architectural discourse. This unrealized project had no less effective than those that had been built, underlining the fact that there were financial

12. Bonnemaison and Eisenbach, Installations by Architects, 2009, 14. 
realities that prohibited the construction of MVRDV's design. The pavilion has still been part of the experimental architecture, whether the project was realized or not, and making a significant impact on both architectural discourse and practice.

Architectural historians and critics have written and speculated about the temporary structures since its experimentation of method could be the key to new architectural practice and thinking. The pavilion also provided both on public and architect to explore and comment on these temporary architectural practices. The limited nature of these temporary structures can be transformed into the creation of opportunities. The pavilions are designed to explore ideas through a time-limited process of design, while the limited budget forces the architect to find new approaches to the issue of 'temporality.' Architects can use temporary structures as laboratories for new approaches that have never been attempted or achieved in architectural practice.

\section{Representation of the Future Architecture as a New Vision}

When the German Pavilion was opened at the 1929 Barcelona Exhibition, Mies van der Rohe questioned the function of the exposition and suggested that the exhibition making money could not be related to the current situation, but should be evaluated based on its accomplishments in the cultural field. ${ }^{13}$ Today, the exposition must be the laboratory to identify new solutions in both technology and industry, as the temporary structure can able to change the world, architecture as well as the architectural perception. In this way, future expositions will also be necessary for architecture, technology, and industry in the forming of future architectural styles and techniques.

While searching for what the future of architecture might be and how their experimentation can be represented, the architects of the temporary structures experience new ways of architecture. This small-scale and time-limited practice can be the key to the future of the architectural practice. The pavilion design can provide the clues of future architecture and also be a key to the future project of the architect that can regenerate the idea, which he/she used for the design of the pavilion and used as a concept. Oscar Niemeyer designed the 2003 Serpentine Pavilion as a summary of his architectural design style in London (Figure 4). He described his pavilion as a flavor of everything that characterized his work, which was based on a cantilever. At the very beginning of the design process, he envisioned something floating above the ground. In the exterior, the simple whiteand-red formulation was set on the lawn, creating white curves and red planar surfaces that Niemeyer stated that the mountains and women's bodies inspired him.

Niemeyer's pavilion was based on an integration of the idea of temporality and permanence, going beyond the constraints that permanent buildings usually required. When choosing the materials, he decided that concrete was not an appropriate material for a temporary structure but could not give up the idea. Since

13. B. Reyner, Theory and Design in the First Machine Age (The United States of America: The MIT Press, 1980), 321-322. 
it was made of concrete and steel, the pavilion appeared more like a permanent addition to the park than the previous structures. The combination of red and white and the use of concrete became the signs of Niemeyer. In 2005, two years after the Serpentine Pavilion, his design of the Ibirapuera Auditorium in Sao Paulo, Brazil, adopted the same curvilinear forms and white-red combination (Figure 5).

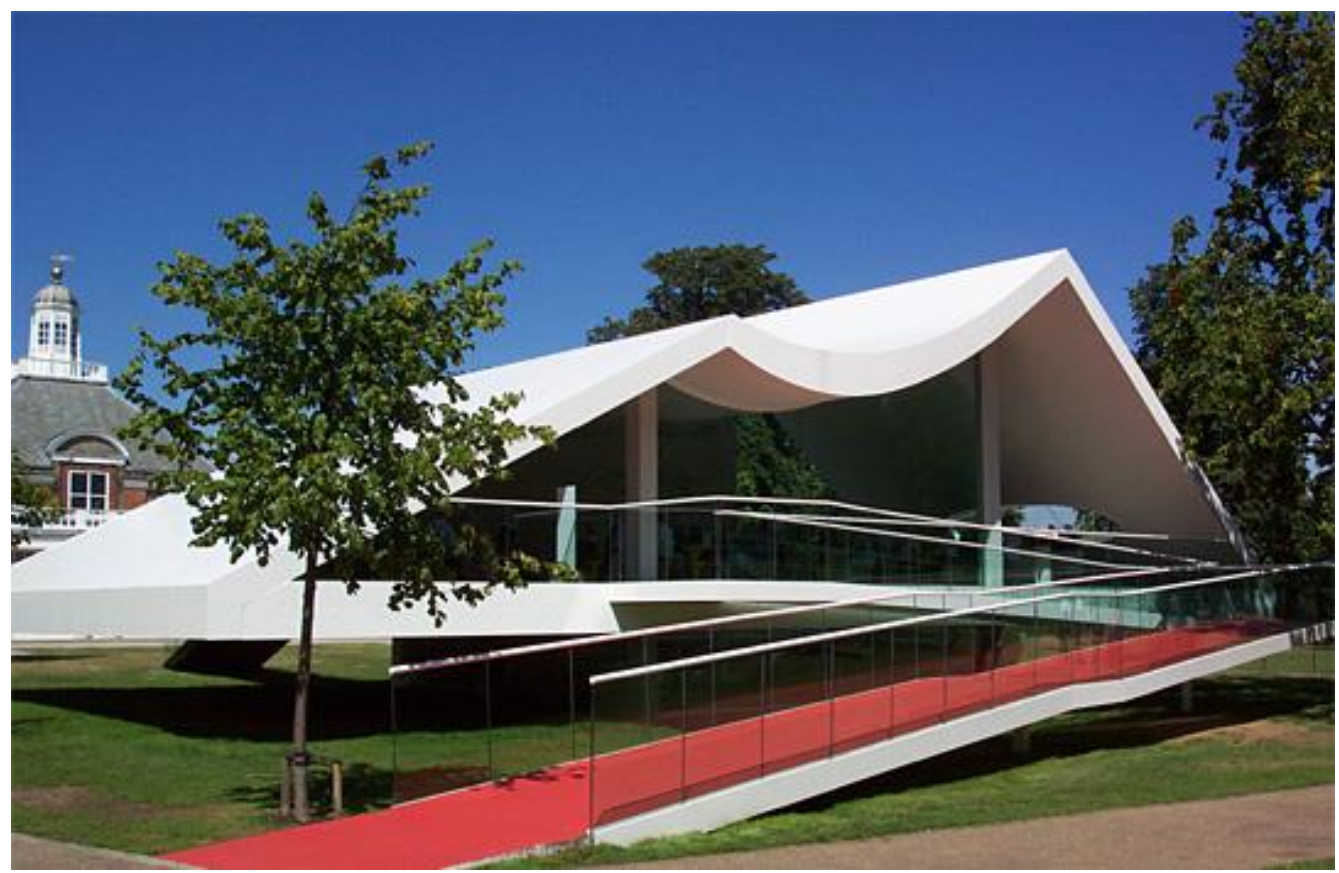

Figure 4. The 2003 Serpentine Gallery Pavilion by Oscar Niemeyer Source: Serpentine Gallery 5 May 2018. www.serpentinegallery.org.

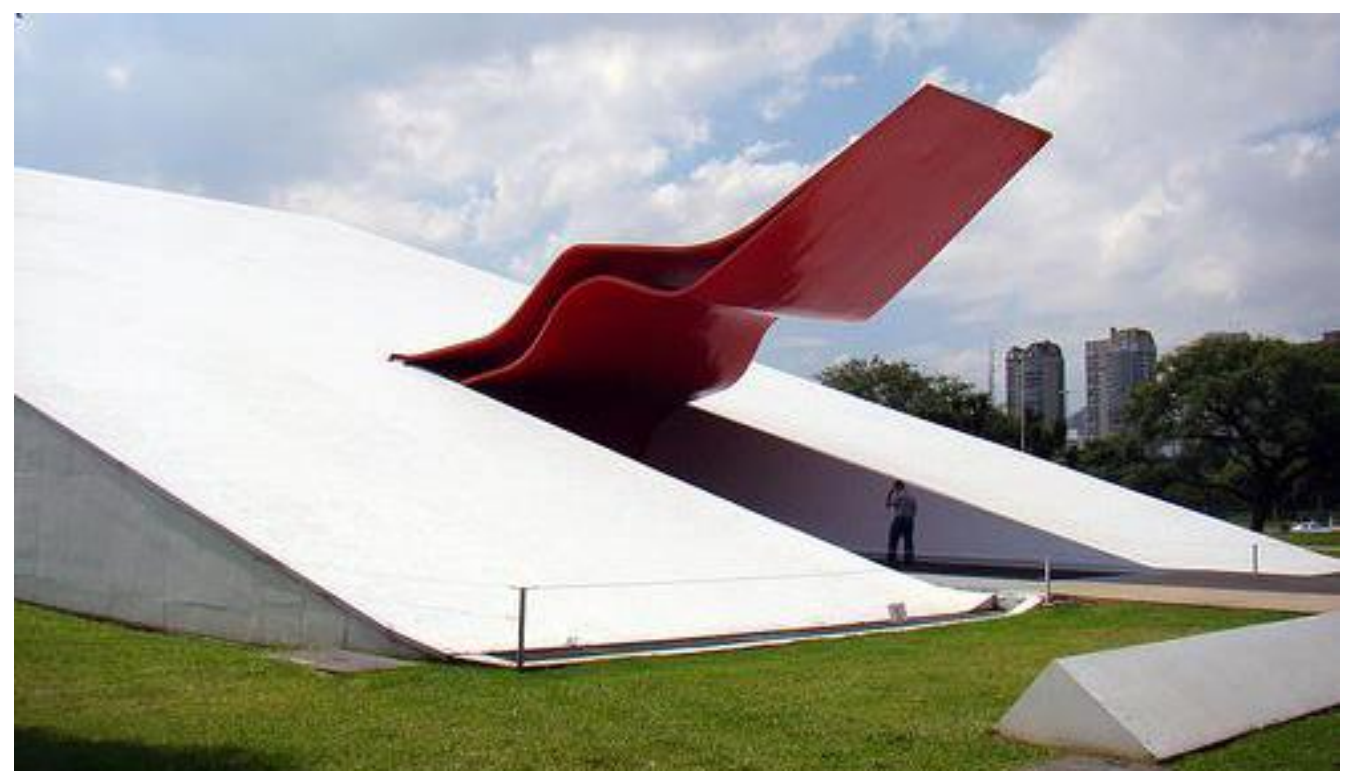

Figure 5. Ibirapuera Auditorium by Oscar Niemeyer, Sao Paulo, Brazil 2005 Source: Archdaily 5 May 2018. www.archdaily.com. 
The innovative architectural design allows architects to explore new approaches and methods in terms of the small-scale temporary structures. These structures are encouraged to find new solutions and creative ways of designing a 'new' in architecture. While designing temporary structures, architects can discover future architectural solutions. Pavilions provide an opportunity to redefine and reinterpret the boundaries and components of conventional architecture as an example of temporary structures.

Pavilion design is valuable for exploring new architectural creative approaches that may form part of the architecture of the future. The possibilities of the verb 'to be' represent the past, present, and also the future can be developed with researchers. The experimental design is a gateway to future architecture and its impact on the world far exceeds the simple provision of temporary structure types. Temporary architectural practices can influence contemporary architecture and the perception of the architects by making open-minded statements about the role, function, and quality of new spaces, and these statements may be used by architects in future projects while providing both architectural history and discourse with conceptual and practical backgrounds.

\section{Re-invention of the 'Pavilion' by Architects}

The pavilion definition has no explicit limitation and boundary. In each case, while designing such temporary structures, the architects redefine and set up their own rules. Zeynep Çelik mentions about the values of temporality in architectural practice and discourse that expositions have served as laboratories for the experiencing of new architectural forms, compositions, materials, and methods, and indeed, no architectural examples of the late $19^{\text {th }}$ century would exclude the Eiffel Tower or the Galerie des Machines, which embodied the new aesthetics of technology. Not only expositions, but also pavilions also reflect the changing tendencies in architecture ${ }^{14}$ and do so with remarkable innovations, leaving plenty of curative marks in the minds of admirers, architects, and critics alike.

The pavilion is a way to explore architectural ideas and design concepts without permanence constraints and opens new opportunities for architects to experience new tendencies in their future architectural practices. The definition of the term 'pavilion' cannot be defined with any certainty since it changes concerning the interpretation of the architect. Based on a re-exploration of space with new materials, the architect can innovatively redefine temporality through the pavilion and can also experience changing tendencies in architecture in terms of these temporary structures.

Rem Koolhaas did not want to reinvent the tradition of the pavilion in the Serpentine case. ${ }^{15}$ Rather, he concentrated in particular on the 'space' of the pavilion since he believed in the power of the pavilion. The main objective of his design was to redefine the space within a temporary situation, stating that the

14. Zeynep Ç. Displaying the Orient: Architecture of Islam at Nineteenth-Century World's Fairs (Berkeley: University of California Press, 1992), 6.

15. Jodidio, Serpentine Gallery Pavilions, 2011, VII.06. 
pavilion can only be made possible by events and activities and that space itself is therefore temporary, being changeable according to the circumstances. He proposed to create a dome for the 2006 Serpentine Pavilion, in which he articulated his desire to achieve lightness in the structure through innovatively using new materials, by doing so, designed changeable space based on temporary situations. His pavilion was redefined in terms of the materials he used and the space he created and experienced the potentials of 'inflatable' structures. He also experienced temporality by the working principle of the structure and defined his pavilion as being based on experience, not only the temporary structure but also the transient situations of the structure.

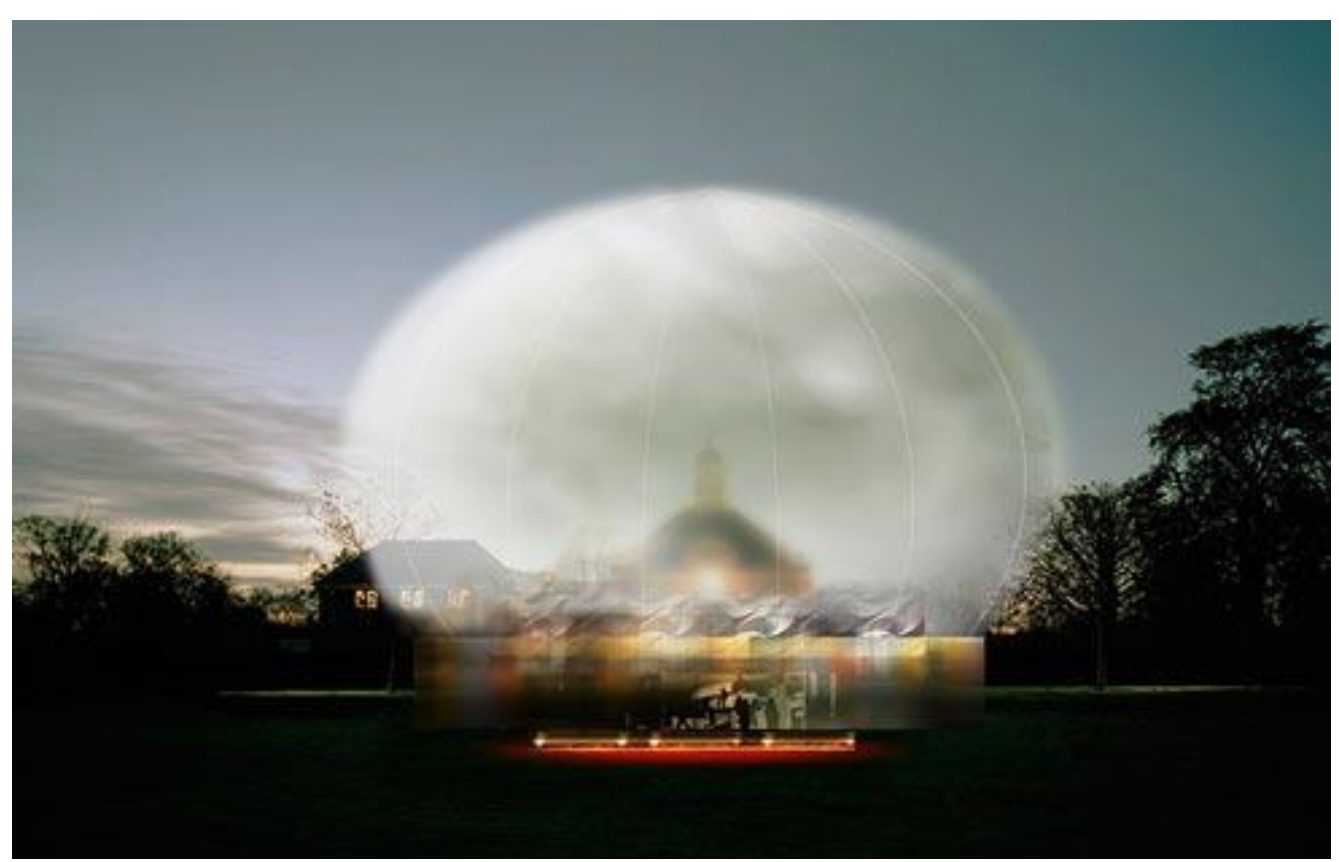

Figure 6. The 2006 Serpentine Gallery Pavilion - 'Cosmic Egg' by Rem Koolhaas Source: Serpentine Gallery 5 May 2018. www.serpentinegallery.org.

Koolhaas' 'Cosmic Egg' aimed towards 'lightness' by the use of new materials in an innovative way and redefined the term 'pavilion' thorough collaboration of both materials and architectural space that was defined in terms of 'air' (Figure 6). This balloon would rise in fine weather and allow air to circulate inside the sphere, but when the colder weather it fitted inside the walls. The strength of its changeable form depending on the activities and weather conditions could be considered as 'unique' to this temporary architectural design. Sarah Bonnemaison and Ronit Eisenbach stated that these inflatable structures could be easily built and quickly erected, and that the curvatures of air-supported structures challenge the linearity that was the mainstream of Modernism. ${ }^{16}$ Due to the curvature form of its dome, this pavilion was distinguishable from other Serpentine Pavilions. The architect of the pavilion was interested in the temporary conditions of the pavilion that was determined by the balloon. By doing so, the

16. Bonnemaison and Eisenbach, Installations by Architects, 2009, 19. 
visitors of the pavilion were able to experiment with the changeable boundaries of this architectural space (Figure 7).

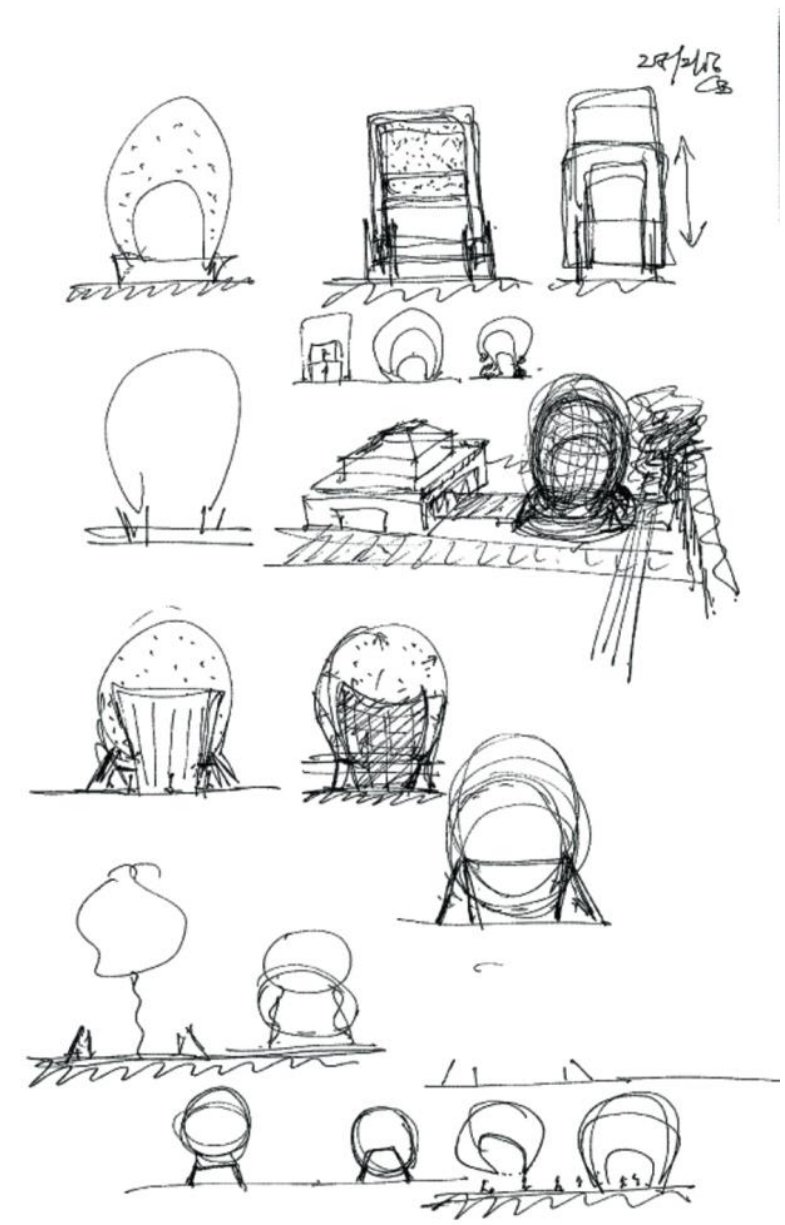

Figure 7. The Sketch of the 2006 Serpentine Gallery Pavilion by Rem Koolhaas Source: Serpentine Gallery 5 May 2018. www.serpentinegallery.org.

With these structures, the architects redefined and revamped temporality in architecture, and while their designs were focused on the same concept, their vision, understanding, perception, interpretation, and end product have been remarkably different. In 2000, Zaha Hadid reinvented the idea of a tent or marquee in her design of the Serpentine Pavilion (Figure 8). In Nikolaus Pevsner's Dictionary, 'tent' is defined as 'a portable shelter that is a tensile structure erected in place by a membrane stretched tightly and attached to the ground with ropes, ${ }^{17}$ which fits in with what Hadid created, being a triangulated tensile canvas membrane and triangulated steel frame structure. By creating an airy roof form, she redefined the idea of portable shelter. The concept of the pavilion was also a reinvention of the 'tent,' although its primary purpose was to design the pavilion without permanent architecture limitations.

17. Fleming, Honour and Pevsner, Dictionary of Architecture and Landscape Architecture, 1999, 567. 


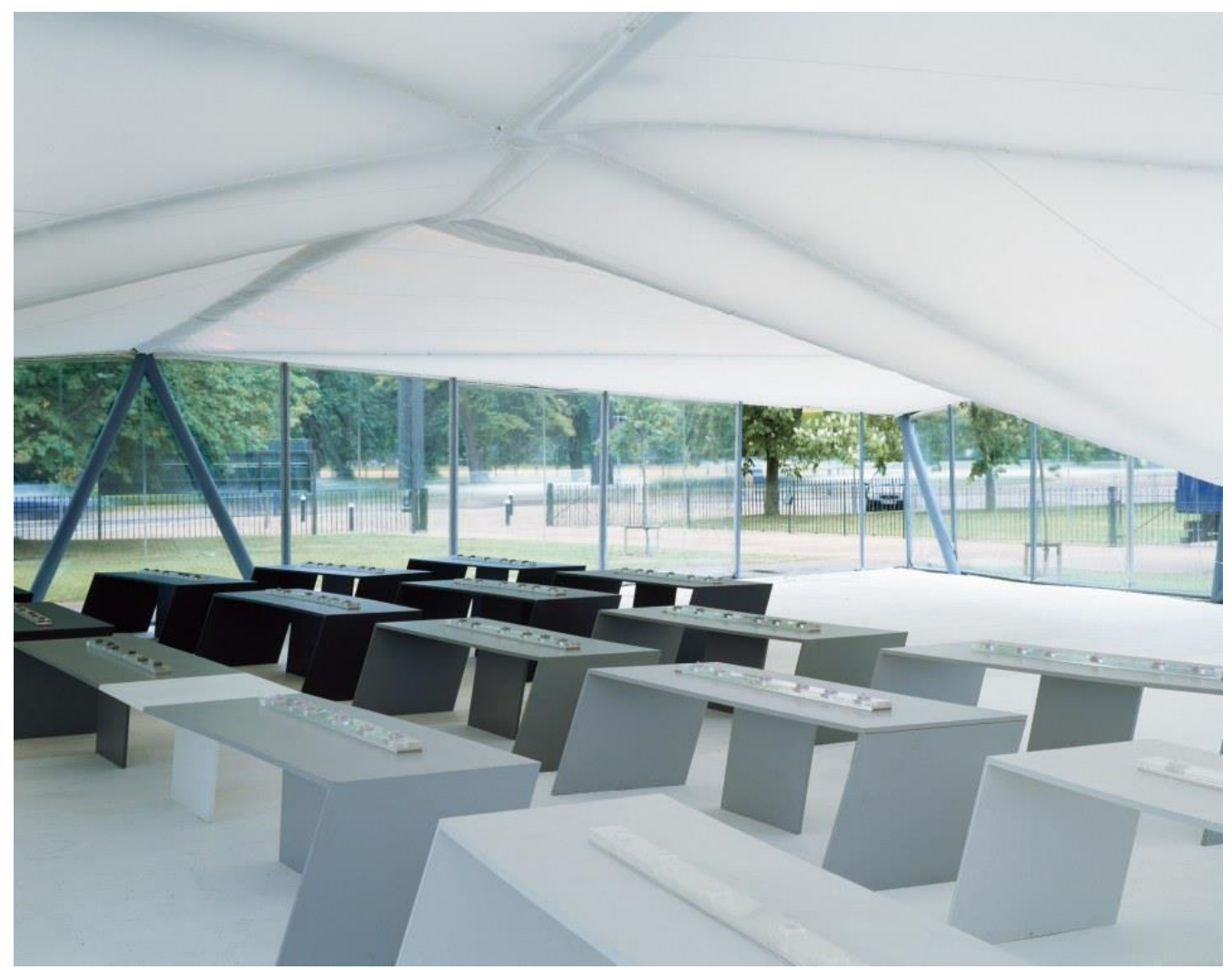

Figure 8. The Interior of the 2000 Serpentine Gallery Pavilion by Zaha Hadid Source: Serpentine Gallery 5 May 2018. www.serpentinegallery.org.

'There's the tradition of making pavilions, which in a sense are not real buildings. It is a display-oriented trajectory, from the large exhibitions of the $19^{\text {th }}$ century to modern ones like Frieze Art Fair. So, throughout the history of the relationship between the park and the city, between the Serpentine Gallery and the park, between the Serpentine Gallery and the pavilion, we see an ongoing negotiation of what constitutes reality. This determines the degree to which we allow people to understand the potential of this construction as a means to reevaluate themselves in relation to the surroundings. ${ }^{, 18}$

Olafur Eliasson's quote revealed his thoughts related to the potentials of pavilion design. He clarified that although the pavilion cannot be seen as a building, it created a real relationship with its context and related to the surroundings. Its relationships could be redefined by each architect, as while each pavilion was located in the same context, each outing exposes itself with a different architectural perception, and each year the pavilion's users experienced and encountered the various potentialities of these temporary structures with different and unique observations.

Through redefining the pavilion, one regulated a new relationship among the public, the architect, the context, and the pavilion itself. As Eliasson denoted, Daniel Libeskind was interested in the relations of the pavilions and redefined the pavilion with its surroundings. Libeskind referred to the pavilion as a means of

18. Jodidio, Serpentine Gallery Pavilions, 2011, VIII.06. 
exploration/discovery, claiming that it had a powerful effect on the place on which it stands and leaves an afterimage. Moreover, he went on to suggest that the pavilion indicated of what new architecture might be and what might have come next in architectural practice and discourse. The pavilion had a physical and aesthetic impact on the space in which it was erected, as it might be a new architecture in a town or a city. Designing a pavilion was a way of experimenting and exploring new architecture, offering a new relationship with its context. The 2001 Serpentine pavilion encouraged the public to come, see and experience it, and the lack of walls made it possible to experience and observe the pavilion's direct link with its surroundings, penetrating the relationship between the interior and exterior of the pavilion, which also provided free of movement (Figure 9).

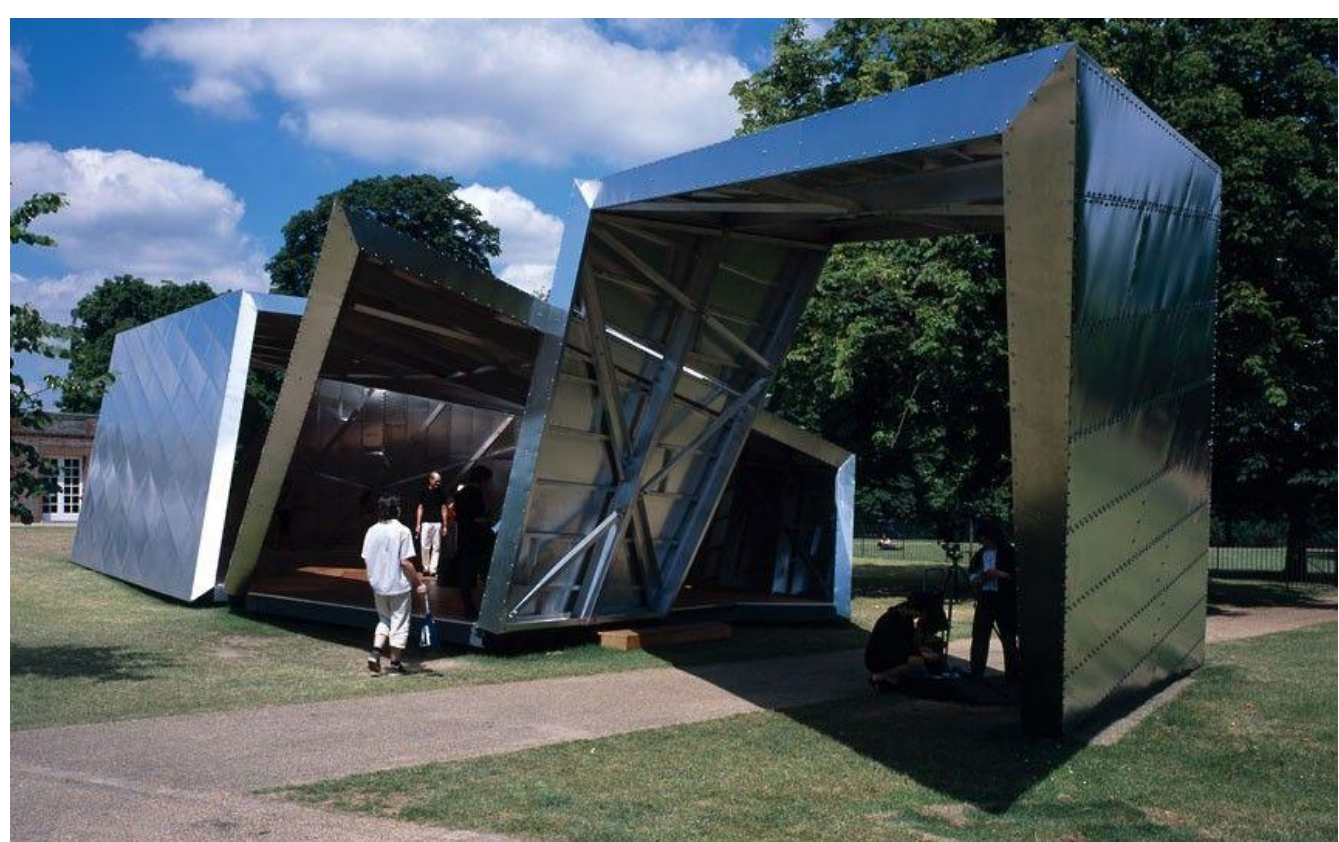

Figure 9. The Context Relationship of the 2001 Serpentine Gallery Pavilion by Daniel Libeskind

Source: Serpentine Gallery 5 May 2018. www.serpentinegallery.org.

As stated by José Luis Sert in 'On Windows and Walls,' the development of new methods of construction and new representational techniques opens the door for a rethinking of the ancient tradition of the relationship between the exterior and the interior through the openings. ${ }^{19}$ The potentials of opportunities have changed in parallel with technological developments. A new relationship has been created between the interior and exterior components of a structure. The openings have served as a picture of nature from the inside to the outside or vice versa. New methods and new technologies represent a compelling force for the discovery of a new way of thinking in architectural discourse and practice. SANAA designed the 2009 pavilion as a continuum aluminum cloud over the lawn of the Serpentine Gallery, intending to create a pavilion that would provide a continuity of

19. Puente, The Exhibition Pavilions: 100 Years, 2000, 5. 
experienced space between the park and the Gallery building. The pavilion resembled a simple floating aluminum roof that was drifting freely among the trees, like smoke, forming a continuum roof between the park and the gallery itself. There was no boundary between the exterior and the interior, as SANAA reinvented the pavilion based on the integration of these spaces being integrated (Figure 10).

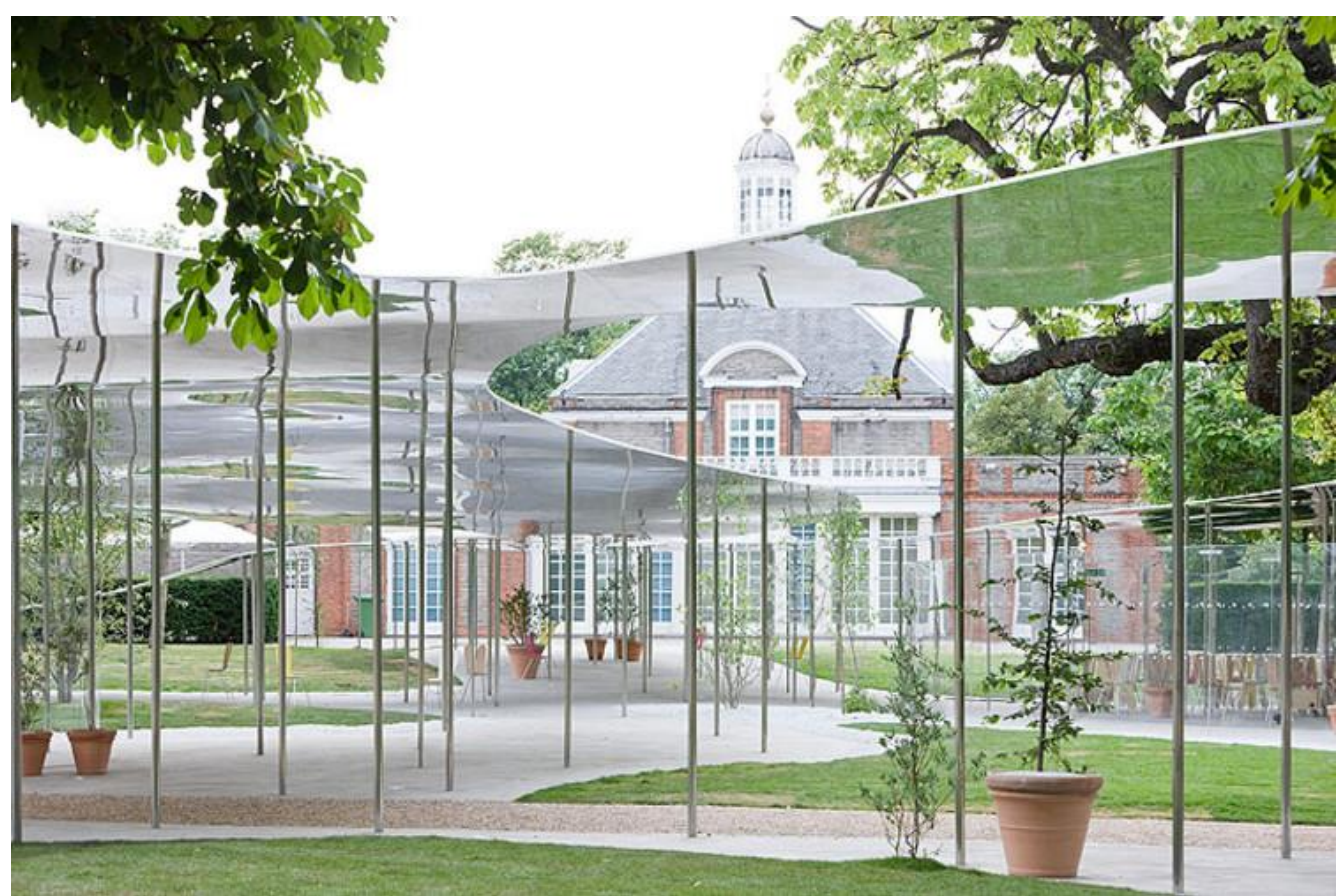

Figure 10. The Continuity of the 2009 Serpentine Gallery Pavilion by SANAA Source: Serpentine Gallery 5 May 2018. www.serpentinegallery.org.

The architects of the Serpentine Gallery Pavilions set forth their (re)definitions, while designing these temporary structures. Both redefinitions play a role in showing and experiencing the new developments and tendencies in architecture, leaving impressive and curative marks in both the architect's mind and the observer's mind in terms of the generation process of the pavilion and the end product of the design. A redefinition of the pavilion can serve as a laboratory for understanding the limitations of temporary architecture. These structures have been considered by the architects as a way of researching, experiencing, exploring and achieving a 'new' that they have never before adopted in their previous architectural practices and can also can be redefined as a regulator of the new relationship among the public, the architect, the context and the pavilion itself.

\section{Conclusions}

This study introduces the idea of 'experimentation in architecture' as an inevitable component in the production and design of the pavilions, given the powerful relationship it forms among the domains of architectural research, 
discourse as well as practice. While offering new rules and classifications for structural problem solving, experimentation produces a direction towards thinking to allow new design ideas, new methods, and new materials in architecture. In architecture, this 'new' approach focuses on seeking events, searching, witnessing an opening up of new possibilities related to space design. Experimental architecture is integrated with real-world conditions and also can be evaluated and tested as an agent to expand architecture's limit as a discipline.

In the domain of architectural discipline, this paper focuses primarily on the pavilion as an object of experimental architecture. Temporary architecture has been argued to establish new relationships that differ from those found in more permanent structures by expanding the boundaries of the spatiality of permanent architecture. Therefore, this study has argued that, due to its small scale and transitional nature, the design of temporary architecture can serve as a foundation for experimentation, and can be considered as a 'laboratory' in architectural practice in terms of using new materials and methods. Hence its very nature challenges the permanence of architecture and allows the architect the ability to experience new tools and concepts in the field.

The main objective of this study is to introduce the possibilities and potentials of temporary structures of the Serpentine Gallery to understand the boundaries of experimentation. The Serpentine Pavilion architects have reinterpreted this temporality through their designs, so an investigation into the series of pavilions can provide an understanding of creativity in experimental architecture. This experimentation has formed part of the future architecture and developed through researches into the potentials of influencing contemporary architecture, and part of this study involves a redefinition of the pavilion, in that there is no precise definition of what a pavilion is. Pavilion design has been regarded as making a great connection to future architecture as innovative models of what will become more extensive construction.

To conclude, the experimental architectural design is valuable for the exploration of new creative architectural approaches that may form part of future architecture. The possibilities of the verb 'to be' represent the past, present, and also the future can be developed with researchers. The experimental design is key to future architecture and can influence the world in a way that far beyond the simple provision of temporary structures. Temporary architectural practices can change contemporary architecture, and the perception of the architects that make architects in future projects may use open-minded statements about the role, function, and quality of new spaces and these statements, thus providing both architectural history and discourse with conceptual and practical backgrounds.

Bibliography

Banham, R. Theory and Design in the First Machine Age. The United States of America: The MIT Press, 1980.

Bonnemaison, S. and R. Eisenbach. Installations by Architects. New York: Princeton Architectural Press, 2009. 
Çelik, Z. Displaying the Orient: Architecture of Islam at Nineteenth-Century World's Fairs. Berkeley: University of California Press, 1992.

Fleming, J., H. Honour and N. Dictionary of Architecture and Landscape Architecture. England: Penguin Books, 1999.

Jodidio, P. Serpentine Gallery Pavilions. Spain: Taschen, 2011.

Le Corbusier. "Architecture: The Expression the Materials Methods of our Times?: In Rethinking Technology. Edited by William Braham and Jonathan A. Hale. The United States of America and Canada: Routledge, 2007.

Lodder, C. Russian Constructivism. CT; London: Yale University Press, 1993.

Puente, M. The Exhibition Pavilions: 100 Years. Barcelona: Editorial Gustavo Gili, SA, 2000.

Smithson, P. "The Masque and the Exhibition: Stages Toward the Real." In Language of Architecture: Lectures, Seminars, and Projects. International Laboratory of Architecture and Urban Design. Edited by Giancarlo Di Carlo. Urbino, Florence: Sansoni, 1982.

Tuncbilek, G. Temporary Architecture: The Serpentine Gallery Pavilions. Master Thesis. Turkey: Middle East Technical University, 2013. 
